\title{
Relationship between respiratory muscle function and quality of life in sarcoidosis
}

\author{
R.M. Wirnsberger*, M. Drent*, N. Hekelaar**, M.H.M. Breteler+, \\ S. Drent ${ }^{+}$, E.F.M. Wouters*, P.N.R. Dekhuijzen**
}

Relationship between respiratory muscle function and quality of life in sarcoidosis. R.M. Wirnsberger, M. Drent, N. Hekelaar, M.H.M. Breteler, S. Drent, E.F.M. Wouters, P.N.R. Dekhuijzen. (CERS Journals Ltd 1997.

ABSTRACT: In sarcoidosis, pulmonary and general symptoms often do not correlate with radiographic stage and routinely performed lung function tests. Asymptomatic muscle involvement in sarcoidosis is common, but little is known about respiratory muscle involvement. The aim of this study was to investigate any relationships between persistent complaints and/or quality of life and respiratory muscle strength and endurance, respectively.

Measurements of maximal inspiratory and expiratory mouth pressures (PI,max and $P \mathrm{E}, \mathrm{max})$, respiratory muscle endurance and routine lung function were made in 18 patients with sarcoidosis. To assess health status and quality of life, patients completed the Sickness Impact Profile (SIP).

Respiratory muscle strength and endurance time were lower in the patient group than in a group of healthy controls $(p=0.05)$. Compared to a general population, the patients with sarcoidosis were found to be limited in physical and psychosocial functioning. The respiratory muscle endurance time correlated with the SIP subscales "mobility" ( $r=-0.56 ; p<0.01)$, and "body care and movement" $(r=-0.79$; $\mathrm{p}<\mathbf{0 . 0 0 1}$ ). The total lung capacity (TLC), inspiratory vital capacity (IVC) and forced expiratory volume in one second (FEV1) were normal in all subjects.

In conclusion, patients with sarcoidosis and normal lung function showed reduced respiratory muscle strength and endurance time. Correlations were found between these indices and both symptoms and certain Sickness Impact Profile domains. Therefore, we suggest inclusion of measurements of respiratory muscle strength in the assessment and follow-up of patients with sarcoidosis.

Eur Respir J 1997; 10: 1450-1455.
*Dept of Pulmonology, University Hospital Maastricht, The Netherlands. **Dept of Pulmonology, Academic Hospital Nijmegen, The Netherlands. +Dept of Clinical Psychology and Personality, University Nijmegen, The Netherlands.

Correspondence: M. Drent

University Hospital Maastricht

Dept of Pulmonology

P.O. Box 5800

6202 Maastricht

The Netherlands

Keywords: Lung function quality of life

respiratory muscle strength sarcoidosis

Received: September 121996 Accepted after revision April 281997
Sarcoidosis is a multisystem disorder, which can affect essentially every organ of the body [1]. The parts of the body most frequently involved are the lungs, lymph nodes, skin, eyes, muscles, heart and joints, and, therefore, symptoms vary considerably. In sarcoidosis, disease activity does not necessarily indicate a progressive or fatal course [2]. Even though the active disease often subsides spontaneously, an indication of activity is necessary in order to monitor the course of the disease and to guide treatment, should the clinical situation justify it $[2,3]$. Whilst there is no single test that accurately reflects the progression of sarcoidosis, clinical examination, chest radiography and lung function tests are used to evaluate and monitor the disease process. Techniques useful in assessing the extent and severity of granulomatous inflammation and fibrosis are: 1) serum markers, including serum angiotensin converting enzyme (sACE); 2) ${ }^{67} \mathrm{Ga}$ scan; 3) bronchoalveolar lavage (BAL); and 4) high resolution computed tomography (HRCT) [2, 4]. When indicators of disease activity, such as radiographic abnormalities, lung function impairment and sACE, return to normal, nonspecific symptoms, such as fatigue and reduced exercise tolerance, may persist.
In a previous study, we found that the quality of life measured by the Sickness Impact Profile (SIP) was related to the perception of complaints, but not to disease activity as conventionally assessed [5]. The SIP is a generic health status instrument, which is intended to measure the impact of sickness rather than to objectively measure the presence of disease [6]. It is an individual's own experience of illness perceived through its effect on daily activities, feelings and attitudes [7].

Asymptomatic granulomatous muscle involvement in sarcoidosis has been reported with a prevalence of 50 $80 \%$ [8], whereas symptomatic muscle involvement is much less common (range 1.4-2.3\%) [9]. The symptomatic involvement that has been described varies from a palpable nodular type to an acute myositis, and a chronic myopathic type [9-12]. Usually, patients present with pain, weakness and muscle atrophy [13]. Little is known, however. about the frequency of respiratory muscle involvement [14].

The aim of this study was to investigate whether there is a relationship between persistent complaints or quality of life disturbance and respiratory muscle function in a population of patients with sarcoidosis. Therefore, 
the relationships between respiratory muscle strength, endurance time, and the SIP scores and subscores were evaluated.

\section{Materials and methods}

\section{Subjects}

Eighteen out-patients suffering from sarcoidosis, who attended the Academic Hospital Nijmegen, were studied. The diagnosis of sarcoidosis was based on consistent clinical features, together with biopsy-proven noncaseating epitheloid cell granuloma. The clinical symptoms of the respective patients varied from none (sarcoidosis detected on routine chest radiography) to more or less severe respiratory symptoms or erythema nodosum and arthralgia (i.e. Löfgren's syndrome). None of the participating subjects had any significant medical history that might have influenced quality of life. Patients with significant co-morbidity were excluded.

A control group $(n=18)$, comprising healthy employees of the Academic Hospital Nijmegen matched for age and gender, were used as reference for the lung function tests, respiratory muscle strength and endurance time, as well as peripheral muscle strength. A control group comprising 594 subjects from a general Dutch population (mean age 43 yrs, range 18-75 yrs; 267 males (45\%) and 327 females (55\%)) were used as reference to compare the SIP measurements [15].

\section{Study design}

Initially, 26 patients with sarcoidosis were contacted. Eight declined for various personal reasons. Eighteen patients agreed to participate after giving informed consent. The questionnaires were completed under supervision of a study assistant, to avoid missing data or misunderstanding. In addition, the patients were asked about their smoking history and whether they had any of the following complaints: fatigue, dyspnoea, cough, arthralgia, or erythema nodosum.

At the time the study was performed, seven of the patients still had symptoms, most notably fatigue. Eleven of the 18 patients had not taken corticosteroids during the previous 3 months. The other seven patients were taking corticosteroids during the 3 months prior to the study, with an average prednisone dose of 5.7 $\mathrm{mg} \cdot \mathrm{day}^{-1}$. Five of these seven patients still had symptoms. The mean $( \pm \mathrm{SD})$ sACE level was $16.8 \pm 5.9 \mathrm{U} \cdot \mathrm{L}^{-1}$ (reference value $<20 \mathrm{U} \cdot \mathrm{L}^{-1}$ ). The radiographic stage varied from 0 to III: four patients had stage 0 , two stage I, 10 stage II, and two stage III appearances. Demographic and clinical characteristics of the patients and the control group are summarized in table 1 .

Table 1. - Characteristics of patients with sarcoidosis and control subjects

\begin{tabular}{lcc}
\hline Variable & $\begin{array}{c}\text { Sarcoidosis patients } \\
(\mathrm{n}=18)\end{array}$ & $\begin{array}{c}\text { Control subjects } \\
(\mathrm{n}=18)\end{array}$ \\
\hline $\begin{array}{l}\text { Age yrs } \\
\text { Gender male/female }\end{array}$ & $43(11)$ & $41(11)$ \\
Smoking yes/no & $11 / 7$ & $8 / 10$ \\
Complaints yes/no & $7 / 11$ & $9 / 9$ \\
Time since diagnosis yrs & $7.2(7.1)$ & - \\
\hline $\begin{array}{l}\text { Data are expressed as absolute number or mean, and SD in } \\
\text { parenthesis. }\end{array}$
\end{tabular}

\section{Lung function tests}

Lung function measurements included forced expiratory volume in one second (FEV1), inspiratory vital capacity (IVC) measured with a pneumotachograph, and total lung capacity (TLC) measured using a body plethysmograph (Compactbody; Jaeger, Würzburg, Germany). The best of three efforts was selected. All volumes were expressed as percentages of the reference values [16].

The transfer factor of the lung for carbon monoxide (TL,CO) was measured by the single-breath method (Masterlab; Jaeger, Würzburg, Germany). In order to compare the TL,CO level with the quality of life scores, the values were classified into four ranges: 1) normal ( $\geq 80 \%) ; 2)$ mild decrease (60-80\%); 3 ) moderate decrease (40-60\%); and 4$)$ severe decrease $(<40 \%$ of predicted), according to the American Medical Association classes.

\section{Respiratory muscle strength and respiratory muscle endurance}

Inspiratory and expiratory muscle strength were assessed by measuring maximal respiratory mouth pressures using the method of BLACK and HyATT [17]. Maximal inspiratory mouth pressure $(P \mathrm{I}, \max )$ was measured at residual volume (RV), whilst maximal expiratory mouth pressure $(P \mathrm{E}, \max )$ was measured at total lung capacity (TLC). The equipment used was a pressure transducer (model MP 45-30; Validyne Engineering Corp., Northridge CA, USA). All signals were recorded on a strip chart (type BD 31; Kipp \& Zonen, Delft, The Netherlands). A needle was placed in the proximal end of the mouthpiece to ensure that efforts were performed with open glottis. At least five manoeuvres were performed, until the three highest values were within $5 \%$ of each other. All subjects were seated in the upright position and were wearing a noseclip while performing the tests, and the same instructions were given to each subject by one investigator. Values are expressed in absolute terms and as percentages of predicted values according to WILSON et al. [18].

Respiratory muscle endurance was assessed by measuring the endurance time using a modified threshold loading device as designed by NICKERSON and KEENS [19]. This device has an inspiratory valve, which can be occluded by a weighted plunger. The plunger can be adjusted externally so that patients must generate enough inspiratory pressure to lift the inspiratory valve and allow inspiratory flow. Expiration can be performed without any resistance. The threshold loading device was first tested and validated in healthy subjects before use. There was a very close relationship between the inspiratory pressure $(P \mathrm{I})$ generated and external weight $(\mathrm{W})$ $(P \mathrm{I}=-(0.201126 \times \mathrm{W}+7.4659) ; \mathrm{r}=0.999, \mathrm{p}<0.001 ; P \mathrm{I}$ in $\mathrm{cmH}_{2} \mathrm{O}, \mathrm{W}$ in $\mathrm{g}$ ). The respiratory muscle endurance time was defined as the maximal time (in seconds) during which a subject could sustain breathing against an inspiratory pressure load equal to $70 \%$ of his/her individual $P$ I,max [20]. All subjects first warmed up by breathing against an inspiratory pressure load equal to $15 \%$ of their $P$ I,max during 2 min. Next they were presented with their individual test load and instructed to breathe for 
as long as they could, until they became so tired they could not continue or until they were unable to get enough air. The test was terminated if the respiratory muscle endurance time exceeded $15 \mathrm{~min}$. During the test, the inspiratory pressure was recorded constantly on the strip chart as described.

\section{Peripheral muscle strength}

Quadriceps force was measured on the nondominant side with the subject sitting, both hip and knee in $90^{\circ}$ flexion, the ankle connected to measuring-equipment based on strain gauges. A nonstretching-band was placed around the hip to prevent the subject from lifting up whilst pulling away the lower leg. The force of the hand muscles was also measured on the nondominant side with the subject sitting, the forearm and hand in a direct line with each other and resting on a table, and the fingers enclosing two wooden handles connected to the measuring equipment based on strain gauges. In both tests, at least three isometric contractions were performed until the differences were not more than 5\%. Between each effort there was an interval of $1 \mathrm{~min}$. Values are expressed as kilogram force (kgf).

\section{Health status questionnaire}

Health status and quality of life were assessed with the SIP (Dutch version) [15, 21]. The SIP was designed to assess sickness-related behavioural dysfunction. It provides summary scores for physical, psychosocial, and overall behavioural dysfunction, as well as separate scores for 12 categories of activity. The scores are expressed as percentages of the maximal possible score of dysfunction in that particular category or set of categories [22]. The scores range between 0 and 100. The higher the scores, the stronger the impact of the disease on the individual's life.

\section{Statistical analysis}

The data of the control subjects and patients were compared using Student's t-test for binomial values and Chi-squared test for ordinal values. Differences in personal characteristics were assessed using Chi-squared tests for categorical data and Student's t-tests for continuous data. Correlation among variables was assessed by single regression analysis. Because of the large number of correlations examined, a p-value of less than 0.01 was considered to be statistically significant. All analyses were performed using the Statistical Package for Social Sciences (SSPS).

\section{Results}

Tables 2 and 3 summarize the results of the SIP scores, and the lung function tests, respiratory and peripheral muscle strength assessments, respectively.

The total SIP scores for the patient group were significantly higher compared with the control subjects. In
Table 2. - Average Sickness Impact Profile (SIP) scores for the sarcoidosis patients and a general Dutch population

\begin{tabular}{lcl}
\hline SIP & $\begin{array}{c}\text { Sarcoidosis } \\
\text { patients } \\
(\mathrm{n}=18)\end{array}$ & $\begin{array}{l}\text { Control } \\
\text { subjects } \\
(\mathrm{n}=594)\end{array}$ \\
\hline Alertness behaviour & $9.9(20.7)^{* *}$ & $4.6(12.4)$ \\
Ambulation & $4.1(8.4)$ & $3.0(7.8)$ \\
Body care and movement & $1.7(3.8)$ & $1.9(5.0)$ \\
Communication & $2.5(4.3)$ & $1.1(4.5)$ \\
Eating & $1.1(3.4)$ & $1.0(3.2)$ \\
Emotional behaviour & $5.7(12.3)$ & $4.0(10.0)$ \\
Home management & $6.9(11.3)^{* *}$ & $4.8(11.8)$ \\
Mobility & $2.9(5.6)$ & $2.4(7.6)$ \\
Recreation and pastimes & $10.5(15.8)^{* *}$ & $7.6(14.1)$ \\
Sleep and rest & $14.3(16.9)^{* *}$ & $4.8(8.2)$ \\
Social interaction & $14.0(23.5)^{* *}$ & $4.0(8.4)$ \\
Employment & $12.4(18.8)^{* *}$ & $7.3(20.0)$ \\
Physical dimension & $2.6(4.4)$ & $2.2(5.4)$ \\
Psychosocial dimension & $11.7(18.6)^{* *}$ & $3.5(7.2)$ \\
Total SIP score & $8.0(9.7)^{* *}$ & $3.4(5.6)$ \\
\hline Data are expressed as &
\end{tabular}

Data are expressed as mean, and SD in parenthesis. The score are on a scale ranging $0-100 . * *: p \leq 0.01$, sarcoidosis patients versus controls (Student's t-test).

Table 3. - Lung, respiratory and peripheral muscle function of patients and control subjects

\begin{tabular}{|c|c|c|c|c|}
\hline \multirow[b]{2}{*}{ IVC $\%$ pred } & \multicolumn{2}{|c|}{$\begin{array}{c}\text { Sarcoidosis } \\
\text { patients } \\
(\mathrm{n}=18)\end{array}$} & \multicolumn{2}{|c|}{$\begin{array}{l}\text { Control } \\
\text { subjects } \\
(n=18)\end{array}$} \\
\hline & 99 & (11) & 105 & (12) \\
\hline FEV1 L & 3.1 & $(0.9)$ & 3.6 & $(0.7)$ \\
\hline FEV1 $\%$ pred & & $(10) * *$ & 106 & (12) \\
\hline TL,CO $\%$ pred & 86 & (9) & 100 & (8) \\
\hline TL,CO normal/decreased & $17 / 1$ & & $18 / 0$ & \\
\hline$P \mathrm{I}$,max (at RV) $\quad \underset{\%}{\mathrm{CmH}_{2} \mathrm{O}}$ & $\begin{array}{l}-86.8 \\
96\end{array}$ & $\begin{array}{l}(28.7)^{* *} \\
(27 * *\end{array}$ & $\begin{array}{l}-112.8 \\
130\end{array}$ & $\begin{array}{l}(24.8) \\
(28)\end{array}$ \\
\hline$P$ E, max (at TLC) $\mathrm{cmH}_{2} \mathrm{O}$ & 91.6 & $(31.5)^{* *}$ & 126.1 & (34.8) \\
\hline $\begin{array}{l}\% \text { pred } \\
\text { Respiratory muscle }\end{array}$ & 74 & $(19)^{* *}$ & 107 & (20) \\
\hline $\begin{array}{l}\text { Respiratory muscle } \\
\text { Endurance test completed n }\end{array}$ & 12 & & 17 & \\
\hline Endurance time $\mathrm{s}$ & 756 & $(246)^{* *}$ & 869 & (130) \\
\hline Quadriceps force $\mathrm{kgf}$ & & & & \\
\hline Male & 43.1 & $(14.1)$ & 45.4 & $(9.1)$ \\
\hline Female & 25.6 & (8.4) & 32.5 & $(4.8)$ \\
\hline Hand muscle force $\mathrm{kgf}$ & & & & \\
\hline Male & 48.5 & $(12.8)$ & 52.1 & (8.6) \\
\hline Female & 23.1 & $(6.8)$ & 33.5 & (5.4) \\
\hline
\end{tabular}

Data are expressed as absolute number or mean, and SD in parenthesis. IVC: inspiratory vital capacity; $\%$ pred: percentage of predicted value; FEV1: forced expiratory volume in one second; TL,CO: transfer factor of the lung for carbon monoxide; $P$ I,max: maximal inspiratory mouth pressure; RV: residual volume; $P$ E,max: maximal expiratory mouth pressure; TLC: total lung capacity. ${ }^{* *}: \mathrm{p} \leq 0.01$, sarcoidosis patients versus controls (Student's t-test).

the patients with sarcoidosis, the subscores were significantly higher in the subscales "alertness behaviour", "home management", "recreation and pastimes", "sleep and rest", "social interaction" and "employment" (table 2).

Only one of the 18 patients had a slightly decreased TL,CO. The absolute values for FEV1 as well as FEV1 $\%$ pred were within the normal range for all patients, as also were the VC and TLC. However, FEV1 \% pred was lower in the patients than in the control subjects 
Table 4. - Univariate regression analyses between Sickness Impact Profile (SIP) scores of patients with sarcoidosis and respiratory muscle strengh, endurance time and peripheral muscle strength

\begin{tabular}{lccccc}
\hline SIP & $P$ I,max & PE,max & $\begin{array}{c}\text { Endurance } \\
\text { time }\end{array}$ & HMF & QF \\
\hline Mobility & & & & & \\
r & -0.02 & -0.28 & -0.56 & 0.12 & 0.10 \\
p-value & NS & NS & $<0.01$ & NS & NS \\
Body care and movement & & -0.79 & 0.17 & 0.22 \\
r & -0.30 & -0.07 & -0.001 & NS & NS \\
p-value & NS & NS & $<0.07$
\end{tabular}

HMF: hand muscle force; QF: quadriceps force; NS: nonsignificant. For further definitions see legend to table 3.

$(\mathrm{p}<0.05) . P \mathrm{I}$,max, $P$ E,max, and respiratory muscle endurance time were all lower in the sarcoidosis patients compared to the control subjects $(\mathrm{p}<0.05)$. Only one of the control subjects failed to complete the respiratory muscle endurance test for the 15 min period, whereas six of the 18 sarcoidosis patients did not finish the test $(p<0.05)$. No differences were found in the respiratory muscle strength and endurance time between sarcoidosis patients who were treated with prednisone and those who were not.

Peripheral muscle strength. i.e. quadriceps and hand muscle force, showed no differences between the sarcoidosis patients and control subjects (table 3).

The respiratory muscle endurance time correlated with the SIP subscales "mobility" $(\mathrm{p}<0.01)$ and "body care and movement" $(\mathrm{p}<0.001)$. However, no correlations were found between the SIP scores and PI,max, $P \mathrm{E}$,max and peripheral muscle strength, respectively (table 4). Patients with symptoms $(n=7)$ (table 1 ) showed lower PI,max $(p<0.03)$ and respiratory muscle endurance time $(p<0.005)$, while patients who experienced fatigue $(n=6)$ had a lower $P$ E,max $(\mathrm{p}<0.03)$ compared to those without complaints.

The radiographic stage was related to the SIP subscales "alertness behaviour" $(\mathrm{p}<0.001)$, "emotional behaviour" $(\mathrm{p}<0.001)$, "home management" $(\mathrm{p}<0.005)$ and "social interaction" $(\mathrm{p}<0.001)$. The duration of disease, the FEV1, and the sACE levels showed no relationship with percentile scores of any of the subscales. Furthermore, no relationship between radiographic stage, sACE, respiratory muscle strength, and respiratory muscle endurance time were found.

\section{Discussion}

This study has shown that respiratory muscle strength and respiratory muscle endurance are reduced in patients with sarcoidosis. Patients with the symptom of fatigue had significantly lower maximum expiratory pressures than those without symptoms. A decreased respiratory muscle endurance time suggests the presence of respiratory muscle fatigue. Muscle fatigue has been defined as a condition in which there is a reduction in the capacity for developing force and/or velocity of a muscle in response to a load, and is reversible by rest [23]. In general, muscle fatigue occurs whenever energy demand exceeds energy supply [24]. Applying this to respiratory muscles, fatigue occurs when these muscles work under conditions where there is an imbalance between energy demand and supply [24].
Muscle weakness is a condition in which the capacity for a rested muscle to generate force is decreased [23]. In our patient group, we found decreased $P \mathrm{I}$,max and $P$ E,max, which indicates inspiratory as well as expiratory muscle weakness. Previously, reduced respiratory muscle strength in sarcoidosis was reported by BAYDUR et al. [13], who compared untreated patients suffering from sarcoidosis with control subjects, and found a decrease in maximal mouth pressures $(P I, \max )$ in the sarcoidosis patients. In agreement with this, BADR and SHARMA [14] found respiratory muscle dysfunction in $61 \%$ of a group of sarcoidosis patients. Moreover, in their study, the $P$ E,max was significantly lower than in normal controls [14].

The results of the present and previous studies, therefore, suggest that $P \mathrm{I}$,max and $P \mathrm{E}$,max are related to functional impairment due to sarcoidosis. These results also emphasize the need for an integrative approach in the assessment and therapeutic management of sarcoidosis. It should be noted, however, that the respiratory muscle tests applied in the present study depend on the cooperation of the patient. To the best of our knowledge, nonvolitional tests of respiratory muscle function, such as magnetic or electrical stimulation of the phrenic nerves, have not been reported in these patients.

Inspiratory muscles are the major muscle groups used in supporting the ventilatory demands of exercise, and the effort required to drive the inspiratory muscles during exercise is a major contributor to the sensation of exertional dyspnoea [25]. With weak muscles, greater utilization of the available muscle mass is required to maintain a given external power output, resulting in an increased sense of effort. As a consequence, in persons with weak respiratory muscles, intolerable exertional discomfort and exertional dyspnoea occur at lower power outputs than in those with strong muscles [25]. In the present study, patients with symptoms had a decreased inspiratory muscle strength and endurance time, when compared to those without symptoms. The complaint of "fatigue" was associated with a lower expiratory muscle strength. Moreover, a relationship was found between the $P \mathrm{I}$,max and respiratory muscle endurance time. Thus, reduced respiratory muscle strength in the presence of sarcoidosis may contribute to exercise intolerance independent of impairment in ventilatory function. This conclusion is consistent with that of HAMILTON et al. [25], who showed that in patients with cardiorespiratory disorders, respiratory, as well as peripheral, muscle strength was a significant contributor to symptom intensity and work capacity, in addition to any contribution from ventilatory, gas exchange, and circulatory impairment.

Several factors, such as hypoxaemia, hypercapnia, malnutrition, decreased blood supply to the muscles, drugs, and electrolyte abnormalities, contribute to respiratory muscle weakness and fatigue, e.g. in chronic obstructive pulmonary disease patients $[26,27]$; however, these are unlikely to contribute in sarcoidosis. Which factor or combination of factors is responsible for this effect in sarcoidosis has not yet been established. In the absence of metabolic abnormalities, recent data have emphasized the role of inflammatory products on different aspects of muscle metabolism. As in other immunemediated disorders, most clinical manifestations of 
sarcoidosis are secondary to the direct effect of the accumulation of activated immunocompetent cells in the involved tissues, notably helper T-lymphocytes and macrophages, and by an increased production of different cytokines [28, 29]. These cytokines appear to be produced in inflamed lesions of sarcoidosis and released into the bloodstream [30]. Future identification of these products could lead to specific therapeutic interventions aimed at blocking their effect in the clinical management of patients with inflammatory disorders, such as sarcoidosis.

As previously suggested, impaired respiratory muscle function suggests that the respiratory muscles can be involved in the granulomatous process of sarcoidosis [13]. Many reports have described granulomatous myopathy without overt manifestations of sarcoidosis elsewhere; sometimes a past history of sarcoidosis was suggested. Hence, granulomas in muscles may persist after those in other organs have become inactive or have resolved in patients who have passed through the active generalized stages of sarcoidosis without obvious symptoms [31]. Little is known about involvement of respiratory muscles, as only a few cases have been described [14, $32,33]$. For example, it is not known whether diaphragm and/or intercostal muscle involvement in sarcoidosis is a possible contributory factor to dyspnoea or impairment of vital capacity [31]. However, histological confirmation of respiratory muscle involvement is hard to obtain. Furthermore, myopathy, including disorders of the respiratory muscles, is a well-known sideeffect of corticosteroids [34, 35]. It should be considered especially with higher doses of steroids, in the presence of markedly impaired respiratory muscle strength or continuous treatment with fluorinated steroids [36]. In the present group of patients, only seven had been treated with steroids during the 3 months prior to the study and the doses they received were low. Moreover, the respiratory and peripheral muscle strength did not differ between patients with or without a history of corticosteroid treatment.

The TL,CO is considered by some authors to be the most sensitive index of lung function in sarcoidosis. It is often the first or only index to be decreased [14]. Remarkably, however, in the present study the respiratory muscle force and endurance were significantly lower than in the control group, even though other lung function tests were normal. This suggests that maximal mouth pressure and respiratory muscle endurance time may be more sensitive to functional impairment due to sarcoidosis than are the TL,CO or $\mathrm{VC}$, which have been suggested as the best indices to correlate with working capacity [37]. The relationship between radiographic stage, lung function and exercise abnormality have, however, been variable [38]. Clearly, there is a wide spectrum of tissue inflammation and organ dysfunction within, as well as between, each radiographic stage. KARETZKY and McDonough [38] found that the magnitude of functional impairment may vary widely from the apparent histopathological involvement as reflected by chest radiography and lung volumes. In the present study, we found a relationship between the radiographic stage and impairment in the fields "alertness behaviour", "emotional behaviour", "home management" and "social interaction".
Furthermore, in the present study, the SIP subscales "mobility" and "body care and movement" as well as the presence of symptoms were shown to correlate with respiratory muscle endurance time. However, for both of these latter domains there was no difference between patients and the control subjects. Moreover, our results show that patients with sarcoidosis are limited in physical and psychosocial functioning. They appear to be particularly affected in the fields "sleep and rest", "recreation and pastime", "employment", "alertness behaviour", "home management" and "social interaction", compared to a control group [15]. This diversity illustrates the broad impact of sarcoidosis on patients' quality of life.

In conclusion, respiratory muscle strength and endurance are reduced in patients with sarcoidosis. Decreased respiratory muscle endurance was found to be related particularly to the Sickness Impact Profile subscales "mobility" and "body care and movement". However, no such relationship was found between these latter Sickness Impact Profile subscales and routinely performed lung function tests, such as transfer factor and spirometry. Measuring respiratory muscle function seems to quantify and characterize the functional impairment in patients with sarcoidosis and reflects symptoms, such as fatigue and general weakness, that are otherwise difficult to assess objectively. Therefore, we suggest that measurements of respiratory muscle strength and endurance time could be usefully included in the diagnostic work-up and follow-up of patients with sarcoidosis. Further studies are needed to assess respiratory and peripheral muscle involvement, as well as the relationship with the presence of inflammatory characteristics in sarcoidosis.

Acknowledgements: The authors would like to thank H.M. Jacobs for providing the Dutch SIP control data, M.D.P. Elfferich and L.M.M. Kock for their great help in collecting the data and their advice. Furthermore, they would like to thank Ch. van der Grinten and G. Vissers for technical advice, J. de Vries for statistical assistance, and the lung function laboratory workers, in particular L. van de Pol, for technical assistance and advice.

\section{References}

1. Thomas PD, Hunninghake GW. Current concepts of the pathogenesis of sarcoidosis. Am Rev Respir Dis 1987; 135: 747-760.

2. Sharma OP. Alam S. Diagnosis, pathogenesis and treatment of sarcoidosis. Curr Opin Pulm Med 1995; 1: 392-400.

3. Hunninghake GW, Gilbert S, Pueringer R, et al. Outcome of the treatment of sarcoidosis. Am J Respir Crit Care Med 1994; 149: 893-898.

4. Baudouin SV, du Bois RM. Disease activity. In: James DG, ed. Sarcoidosis and other granulomatous disorders. New York, Dekker, 1994; pp. 153-180.

5. Drent M, Breteler MHM, Kock LMM, Wouters EFM. Quality of Life (QOL) and depressive symptoms in patients with sarcoidosis: a pilot study. Am J Respir Crit Care Med 1996; 153: A279.

6. Bergner M, Bobitt RA, Carter WB, Gilson BS. The Sickness Impact Profile: development and final revision of a health status measure. Med Care 1981; 14: 787805 . 
7. Davies GL, Balart LA, Schiff ER, et al. Assessing health-related quality of life in chronic hepatitis $\mathrm{C}$ using the sickness impact profile. Clin Therapeut 1994; 16: 334-343.

8. Silverstein A, Siltzbach LE. Muscle involvement in sarcoidosis: asymptomatic, myositis and myopathy. Arch Neurol 1969; 21: 235-241.

9. Jamal MM, Cilursu AM, Hoffman EL. Sarcoidosis presenting as acute myositis: report and review of the literature. J Rheumatol 1988; 15: 1868-1871.

10. Stjernberg N, Cajander S, Truedsson H, Uddenfeldt P. Muscle involvement in sarcoidosis. Acta Med Scand 1981; 209: 213-216.

11. Nidiry JJ, Mines S, Hackney R, Nabhani H. Sarcoidosis: a unique presentation of dysphagia, myopathy and photophobia. Am J Gastroenterol 1991; 86: 16791682.

12. Fonseca GA, Baca S, Altman RD. Acute myositis and dermatitis as the initial presentation of sarcoidosis. Clin Exp Rheumatol 1993; 11: 553-556.

13. Baydur A, Pandya K, Sharma OP, Kanel GC, Carlson M. Control of ventilation. respiratory muscle strength, and granulomatous involvement of skeletal muscle in patients with sarcoidosis. Chest 1993; 103: 396-402.

14. Badr AI, Sharma OP. Pulmonary function. In: James DG, ed. Sarcoidosis and Other Granulomatous Disorders. New York, Dekker, 1994; pp. 247-266.

15. Jacobs HM, Luttik A, Touw-Otten FWMM, Melker de RA. The Sickness Impact Profile; results of an evaluation of the Dutch version. Ned Tijdschr Geneesk 1990; 134: 1950-1954.

16. Quanjer PH, Tammeling GJ, Cotes JE, Pedersen OF, Peslin R, Yernault J-C. Lung volumes and forced ventilatory flows. Report working party. Standardization of lung function tests. European Commission for Steel and Coal. Official statement of the European Respiratory Society. Eur Respir J 1993; 6 (Suppl. 16): 5-40.

17. Black LF, Hyatt RE. Maximal respiratory pressures: normal values and relationship to age and sex. Am Rev Respir Dis 1969; 99: 696-702.

18. Wilson SH, Cooke NT, Edwards RHT, Spiro SG. Predicted normal values for maximal respiratory pressures in Caucasian adults and children. Thorax 1984; 39: 535538.

19. Nickerson BG, Keens TG. Measuring ventilatory muscle endurance in humans as sustainable inspiratory pressure. J Appl Physiol: Respirat Environ Exercise Physiol 1982; 52(3): 768-772.

20. Larson JL, Kim MJ, Sharp JT, Larson DA. Inspiratory muscle training with a pressure threshold breathing device in patients with chronic obstructive pulmonary disease. Am Rev Respir Dis 1988; 138: 689-696.

21. Schrier AC, Dekker FW, Kaptein AA, Dijkman JH. Quality of life in elderly patients with chronic non- specific lung disease seen in family practice. Chest 1990; 98: 894-899.

22. Patrick DL, Deyo RA. Generic and disease specific measures in assessing health status and quality of life. Med Care 1989; 27: S217-S232.

23. Macklem PT. The importance of defining respiratory muscle fatigue. Am Rev Respir Dis 1990; 142: 274.

24. Roussos C. Function and fatigue of respiratory muscles. Chest 1985; 88: 124S-131S.

25. Hamilton AL Killian KJ, Summers E, Jones NL. Muscle strength, symptom intensity, and exercise capacity in patients with cardiorespiratory disorders. Am J Respir Crit Care Med 1995; 152: 2021-2031.

26. Dekhuijzen PNR, Gayan-Ramirez G, Decramer M. Does corticosteroid treatment affect the respiratory muscles? Eur Respir J 1993: 6: 465-466.

27. Tobin MJ. Respiratory muscles in disease. Clin Chest Med 1988; 9: 263-271.

28. Drent M, Velzen-Blad van H, Diamant M, Hoogsteden HC, Bosch van den JMM. Relationship between disease presentation of sarcoidosis and T-lymphocyte profile: a study in bronchoalveolar lavage fluid. Chest 1993; 104: 795-800.

29. Shijubo N, Imai K, Shigehara K, et al. Soluble intercellular adhesion molecule-1 (ICAM-1) in sera and bronchoalveolar lavage fluid of patients with idiopathic pulmonary fibrosis and pulmonary sarcoidosis. Clin Exp Immunol 1994; 95: 156-161.

30. Asano M, Minagawa M, Ohmichi M, et al. Detection of endogenous cytokines in sera or in lymph nodes obtained from patients with sarcoidosis. Clin Exp Immunol 1991; 84: 92-96.

31. Rizzato G, Montemurro L. The locomotor system. In: James DG, ed. Sarcoidosis and Other Granulomatous Disorders. New York, Dekker, 1994; pp. 343-373.

32. Ost D, Yeldandi A, Cugell D. Acute sarcoid myositis with respiratory muscle involvement: case report and review of the literature. Chest 1995; 107: 879-882.

33. Pandya KP, Klatt EC, Sharma OP. Sarcoidosis and the diaphragm. Chest 1988; 94: 223.

34. Decramer M, Lacquet LM, Fagard R, Rogiers P. Corticosteroids contribute to muscle weakness in chronic airflow obstruction. Am J Respir Crit Care Med 1994; 150: $11-16$.

35. Weiner P, Azgad Y, Weiner M. The effect of corticosteroids on inspiratory muscle performance in humans. Chest 1993; 104: 1788-1791.

36. Gallagher CG. Respiratory steroid myopathy. Am J Respir Crit Care Med 1994; 150: 4-5.

37. Bradvik I. Use of lung function tests in sarcoidosis. Sarcoidosis 1996; 13: 59-62.

38. Karetzky M, McDonough M. Exercise and resting pulmonary function in sarcoidosis. Sarcoidosis 1996; 13: 43-49. 